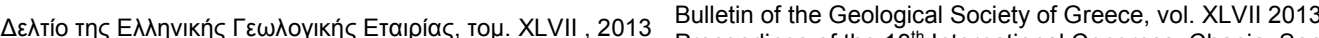
XLVII, 2013 Proceedings of the $13^{\text {th }}$ International Congress, Chania Sept.

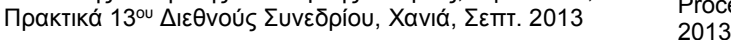

\title{
CHANGES IN FLOOD MORTALITY DURING THE LAST 50 YEARS IN GREECE
}

\author{
Diakakis M. ${ }^{1}$ and Deligiannakis G. ${ }^{2}$ \\ ${ }^{1}$ National and Kapodistrian University of Athens, Faculty of Geology and Geoenvironment, \\ 15784, Zografou, Athens, Greece,Email: diakakism@geol.uoa.gr \\ ${ }^{2}$ Department of Earth and Atmospheric Sciences Mineralogy - Geology Laboratory \\ 75 Iera Odos Str., GR 11855, Athens, Greece
}

\begin{abstract}
This work focuses on the changes that occur in the circumstances under which flood fatalities occur in Greece. To this aim, this paper develops and studies a database of 189 flood-related deaths, between 1960 and 2010, consisting of variables describing the conditions during the time of each incident. Changes in the number and the spatial distribution of fatalities, together with changes in the conditions, the surrounding environment and the demographics of the victims are investigated. Results showed that males, youngsters and elderly people presented an overrepresentation among the decedents, although individuals between 20 and 65 showed a significant increase among the victims, especially during the last decades of the study period. Fatal flood events were found to be approximately equally divided between urban and rural environments. However, fatal incidents appear to gradually migrate from urban centers to rural environments. Vehicle-related fatalities showed a gradual increase, whereas pedestrian victims and indoors incidents show an opposite trend. Fatalities per flood event presented a significant decline, although in absolute numbers, flood deaths did not show a respectively important decreasing trend. Among different causes of death drowning was found to be the most common throughout the study period.
\end{abstract}

Key words: Flood deaths, Flood fatalities, Spatial Analysis, Flood Hazard.

\section{Пєрí $\eta \psi \eta$}

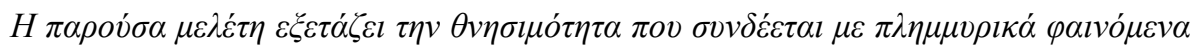

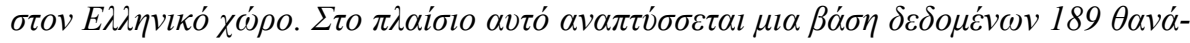

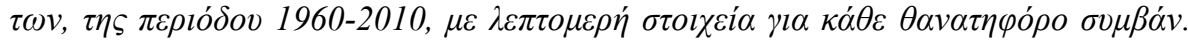

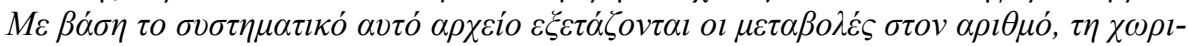

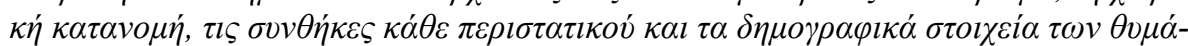

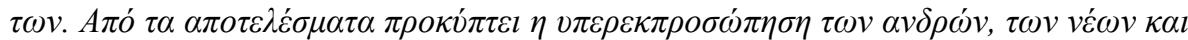

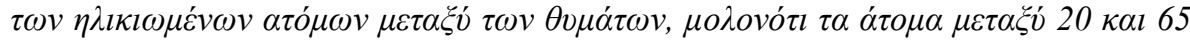

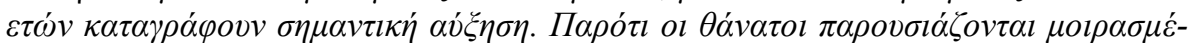

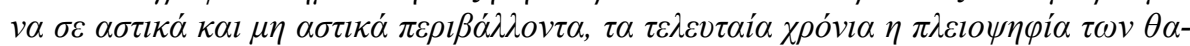

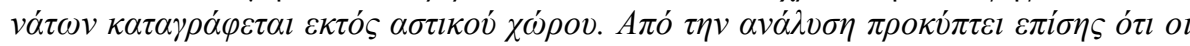

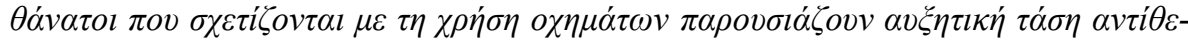

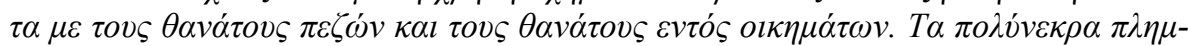

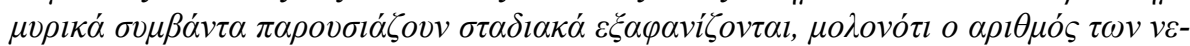

$\underline{\text { XLVII, No } 3-1397}$ 


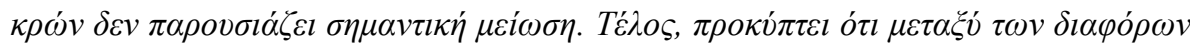

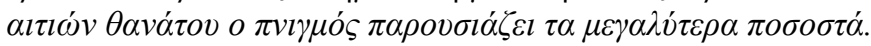

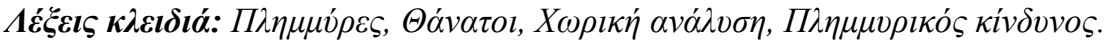

\section{Introduction}

Flooding is one of the most catastrophic types of natural hazards in southern Europe (Guzzetti and Tonelli, 2004, Llasat et al., 2010,) inducing extensive damages and a large number of fatalities every year (Kunkel et al., 1999, Barrero, 2009).

Several studies focus on mortality associated with flooding (Alderman et al., 2012) by examining the factors that affect the vulnerability of individuals (French et al., 1983, Coates, 1999, Rappaport, 2000, Jonkman and Kelman, 2005, Ashley and Ashley, 2008, Bern et al., 1993, Staes et al., 1994). The victims' age is considered one of these factors, as it is suggested that very young and elderly individuals are more vulnerable due to lack physical strength and their inability to flee (Chowdburry 1993, Ashley and Ashley 2008). Regarding the victims' gender several studies show that males are more vulnerable (Coates 1999; French et al. 1983, Rappaport, 2000, Ashley and Ashley 2008) due to their involvement in riskier activities during a disaster and their propensity towards risk taking. However, this distribution is not always verified (Pradhan et al., 2007, Yeo and Blong, 2010, Alderman et al., 2012).

The literature examines also the activity of the victims at the time of the incident (French et al., 1983, Staes et al., 1994, Rappaport, 2000) as a factor affecting vulnerability. It is suggested that the majority of fatal incidents are vehicle-related (French et al., 1983, Staes et al., 1994, Rappaport, 2000, Yale et al., 2003, Drobot et al., 2007, Ruin et al., 2007, Ashley and Ashley, 2008), whereas other activities such as walking, being in a building, attempting a rescue or doing sports, are appearing usually in smaller percentages (Jonkman and Kelman, 2005).

Drowning presents the highest percentages amongst different causes of death, although a number of fatalities is related also to physical traumas, electrocution and heart attacks (Chowdhury et al., 1993, Jonkman and Kelman, 2005). Other vulnerability factors suggested, concern previous flood experiences (Grothman and Greusswig, 2006), time of the day, flood type (Coates, 1999, Jonkman, 2005) and issuance of flood warnings (French et al., 1993, Staes et al., 1994).

Greece is no exception to this flood-rich regime, as the literature shows an abundance of flood phenomena during the last decades (Mimikou and Koutsoyiannis, 1995, Stathis, 2004, Diakakis, 2010, Koutroulis et al., 2010, Diakakis et al., 2011). Nikolaidou and Hatzichristou (1995) developed a catalogue of flood events between 1887 and 1994 identifying 29 catastrophic fatal floods inducing at least 179 fatalities. Diakakis et al. (2011b) studied the flooding history of western Athens recording 76 fatalities in 4 flood incidents and 10 more non-fatal events in this part of the city. Lately, Diakakis et al. (2012) developed a database of 545 flood events, causing a total of 586 fatalities across the country.

Although previous works indicate changes in flooding phenomena in the country (Stathis, 2004, Diakakis et al., 2011a, Diakakis et al., 2012), there is limited information on human vulnerability to floods and how it has changed over the last decades, as social and technological conditions gradually altered (i.e. increase of urban population, improvement of buildings, increase of vehicle use etc.).

Given the limited research carried out in this scientific field and the significance of flood disasters in the recent decades (Lekkas et al., 1997, Koutsoyiannis and Baloutsos, 2000, Diakakis et al., 2011b), this work examines an inventory of flood-related deaths, between 1960 and 2010, in an effort to improve our understanding on flood vulnerability and the circumstances under which these fatalities occur. To this aim, the paper analyzes their spatial distribution, the demographic characteristics of the victims, the incident details and their change over the course of this period.

$\underline{\text { XLVII, No } 3-1398}$ 


\section{Data and Methods}

\subsection{Data}

Primary information on flood events and associated fatalities was based on the database developed by Diakakis et al. (2012). According to this inventory, 189 fatalities were induced by 57 fatal flood events between 1960 and 2010. This catalogue contained data on location, number of fatalities, and date of the floods and was used as the basic record upon which additional information, concerning the circumstances of flood deaths, was aggregated.

Detailed scientific reports (Mimikou and Koutsoyiannis 1995, Mimikou et al., 2002, Skilodimou et al., 2003, Evelpidou et al., 2009, Diakakis et al., 2011) and press articles based on police reports, stored in 13 national newspaper databases such as the Digital Newspaper Collection (2010) of the Greek National Library and the Greek National Newspapers Archive (2010) of the Library of the Hellenic Parliament, were used to obtain details on the victims and the specifics of each incident.

\subsection{Methodology}

Details on the demographics of the victims, their activity at the time and their cause of death were collected. Based on this information, a systematic database was developed. Each entry of this database, corresponding to one fatality, consisted of several variables that offered detailed and objective description of the incident. All deaths included in this database were immediately and directly attributable to a flood event. Long-term health effects and casualties caused by flood disasters that are documented in certain studies (Alderman et al., 2012), were not examined in this work due to lack of data. Each fatality was given one classification in each of the following variables:

1. Name of the victim (for reference purposes)

2. Exact location

3. Date

4. Activity of the victim at the time of the incident

5. Age and gender of the victim

6. Cause of death

7. Type of surrounding environment (urban or rural)

To examine the spatial distribution of fatalities and possible changes in it during the study period (1960-2010), their locations were plotted on the country's map in a GIS environment.

Regarding the activity of the victims, possible classifications included walking, using a vehicle, being in a building, camping, evacuating an open or a confined space and attempting a rescue. Regarding the cause of death, possible classifications included drowning, heart attack (caused during the flood and attributed directly to the events), physical trauma (included individuals that died as a result of being hit by debris, the collapse of a building, physical injuries suffered during the flood or as their vehicle crashed influenced by floodwaters) and electrocution (caused by contact with floodwaters). The temporal evolution of fatalities was analyzed on decadal basis by comparing the total number of deaths and the number of deaths per event. With respect to the distinction between rural and urban areas, it is important to note that the classification "urban" was used only in the case that the surrounding environment of the exact location of the incident was built and consisting of human infrastructure.

Formation of the database allowed the development of a systematic record of data based on evidence fragmented in several reports, provided standardization of information and allowed easy cross reference, comparison and quantitative analysis. After the development of the database, simple mathematical operations were used to quantify the results and examine possible changes.

$\underline{\text { XLVII, No } 3-1399}$ 


\subsection{Data Treatment and Uncertainties}

One source of uncertainty was associated with the non-scientific nature of part of the data. Although press databases have been used before as data sources in the study of natural hazards (Llasat et al., 2009), to deal with the possibility of subjectivity, the variables selected to describe fatalities were specifically chosen in a way that they would not be subject to the reporter's opinion. In addition, to assure an accurate determination of the locations of fatalities, spatial data were crosschecked in two independent sources. In addition, it should be noted that due to unavailability of data regarding the demographics of the country throughout the study period, comparison of the victims' age and gender details with these of the general population, was carried out using the 2001 census (ELSTAT 2001), and should be therefore considered with caution.

\section{Results and Discussion}

During the 50 years of the study period, a total of 189 fatalities were examined. Fatal events were found to occur all over the country, mainly in coastal, low-lying areas (Figure 1). The capital, Athens, showed an increased clustering of deaths, a fact attributed to multiple-fatality events that occurred in the area between 1960 and 1980 (Mimikou and Koutsoyiannis, 1995). Examination of the evolution of their spatial distribution showed changes between the first and the second half of the study period (Figure 1). In particular, the first half of the study period (1960-1985) presents an increased clustering of fatalities near Athens, whereas during the second half fatality locations show a higher dispersion across the country, with the majority of them occurring outside urban centers.

Examination of the surrounding environment showed that $47.1 \%$ of the incidents occurred in urban setting, whereas $46.03 \%$ occurred in rural areas. In $6.88 \%$ of cases this detail was not reported. However, examination of the same variable, in decadal basis, showed that rural incidents present a gradual increasing trend, counter to the urban ones which present a decline (Figure 2). This trend is attributed to the gradual disappearance of flood events with very high fatality figures in urban environments probably due to the improvement of buildings. For instance, during 1961 and the 1977 events (Mimikou and Koutsoyiannis, 1995) in the city of Athens, several victims died due to building collapses.

With regard to the activity of the victims, using a vehicle was identified as the most common activity, followed by individuals that passed away inside buildings, walking, camping and doing sports, attempting a rescue and evacuating a location (Table 1). In 52 cases, the activity was not reported. Regarding the cause of death, analysis showed that drowning presented the highest percentage, followed by physical trauma, heart attack and electrocution (Table 1). In $23.2 \%$ of the cases this detail was not reported.

Examination of the temporal evolution of decedents' activities showed a gradual increase in vehicle-related fatalities and a significant decrease in victims that died as pedestrians or indoors. Attempting a rescue presented a slight increase, whereas evacuating, camping and doing sports showed extended fluctuations but inconclusive trends (Figure 3).

Changes in flood victims' activity are attributed to the increase in use of motor vehicles in Greece. The clear decline of indoor incidents supports also the assumption of improvement in the structural endurance of buildings. The higher percentage of vehicle-related incidents shows accordance with other studies (French et al., 1983 Staes et al., 1994, Rappaport, 2000) and it is ascribed by the literature to the tendency of vehicle occupants to underestimate the risk of entering into a flooded area with a vehicle (Yale et al., 2003, Drobot et al., 2007).

$\underline{\text { XLVII, No } 3-1400}$ 


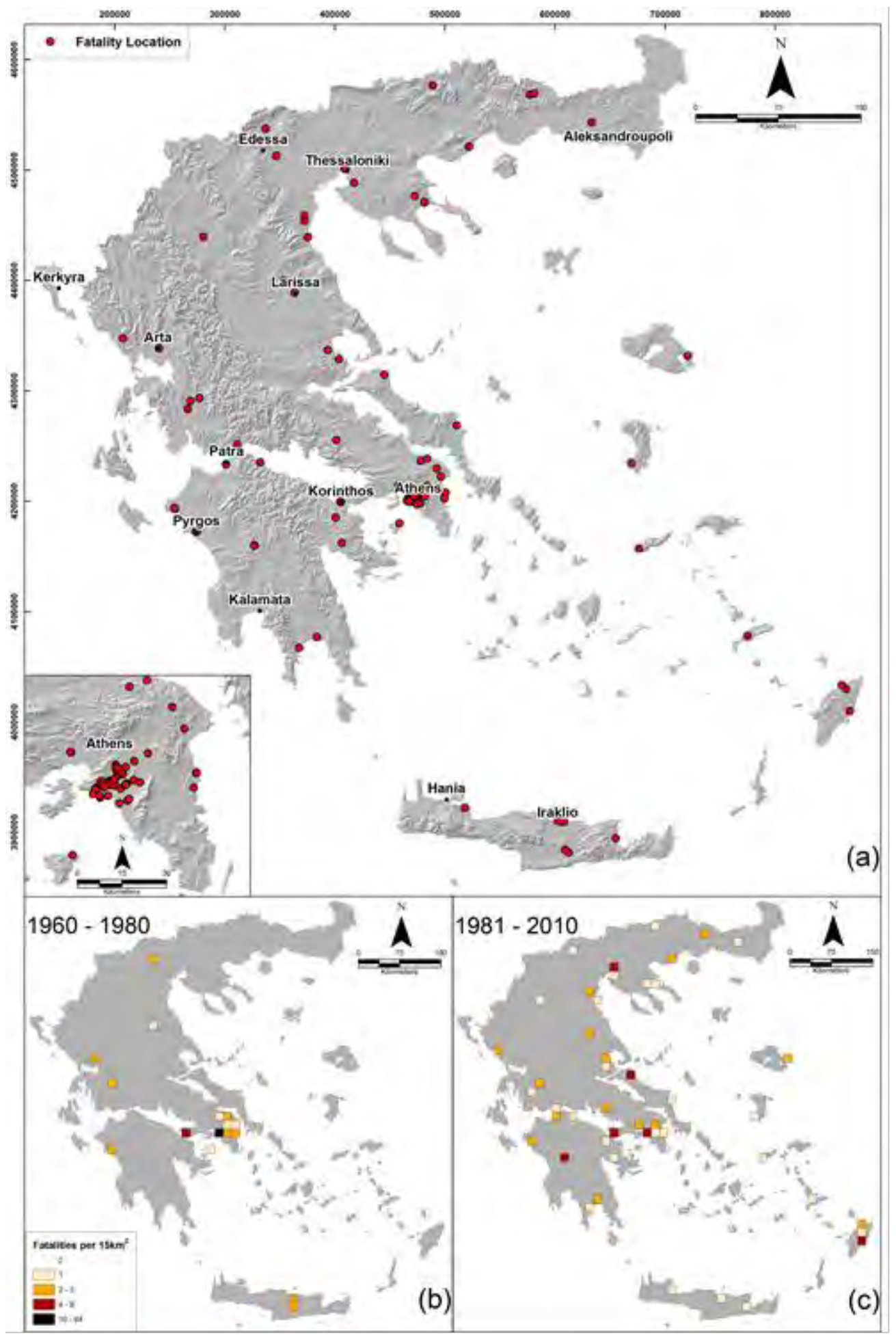

Figure 1 - (a) Spatial distribution of flood fatalities in Greece, between 1960 and 2010 and the changing spatial distribution of them in the two halves of the study period $(b, c)$

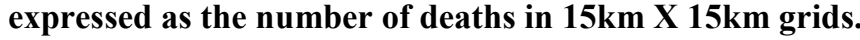




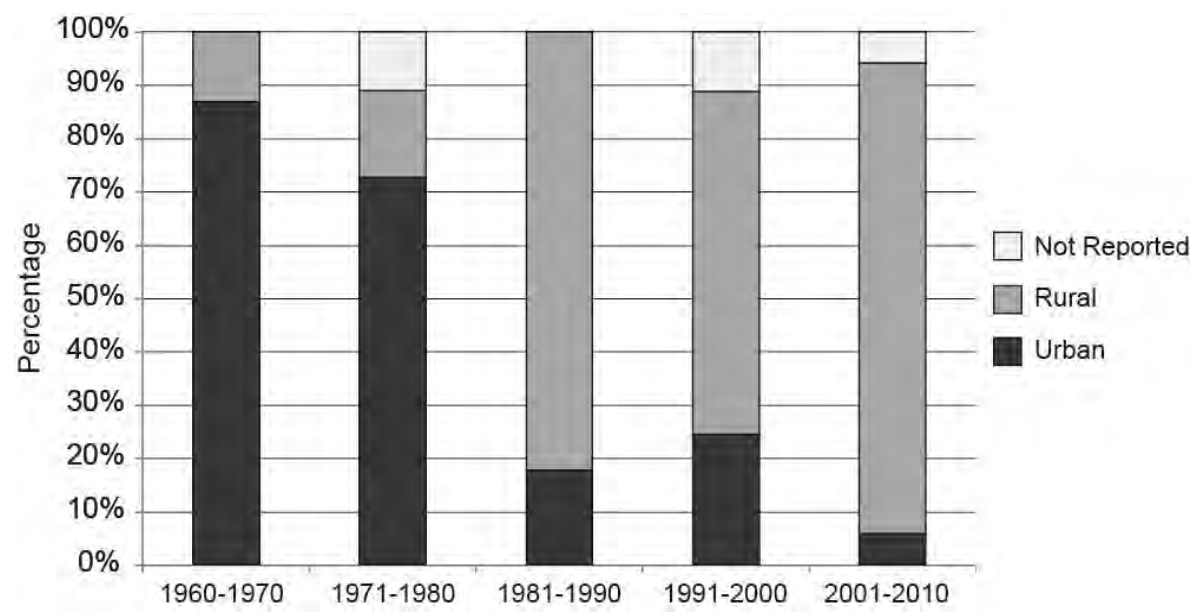

Figure 2 - Distribution of incidents with respect to their surrounding environment, showing a significant increase of rural events and a respective negative trend of urban ones.

Table 1 - Distribution of flood victims in Greece (1960-2010) with respect to their activity and their cause of death.

\begin{tabular}{|l|c|c|l|c|c|}
\hline \multicolumn{1}{|c|}{ Activity } & $\begin{array}{c}\text { No. of } \\
\text { cases }\end{array}$ & $\begin{array}{c}\text { \% } \\
\text { Cause of death }\end{array}$ & $\begin{array}{c}\text { No. of } \\
\text { cases }\end{array}$ & \% \\
\hline Using a vehicle & 57 & 30.2 & Drowning & 119 & 63.0 \\
\hline Being in a building & 28 & 14.8 & Physical Trauma & 19 & 10.1 \\
\hline Walking & 24 & 12.7 & Heart Attack & 4 & 2.1 \\
\hline Camping & 8 & 4.2 & Electrocution & 3 & 1.6 \\
\hline Doing sports & 8 & 4.2 & Not Reported & 44 & 23.2 \\
\hline Attempting a rescue & 7 & 3.7 & & & \\
\hline Evacuating a location & 5 & 2.7 & & & \\
\hline Not Reported & 52 & 27.5 & & & \\
\hline Total & 189 & 100 & Total & 189 & 100 \\
\hline
\end{tabular}

Examination of the evolution of causes of death showed that only negligible changes occurred during the study period.

Regarding the temporal evolution of deaths, significant fluctuations were identified in their numbers, presenting no clear trend during the study period. However, the number of fatalities per event showed a clear decreasing trend (Figure 4), showing too the gradual disappearance of multifatality events.

With respect to the victim demographics, it was found that the majority of the victims were males (58.74\%), whereas females recorded a much smaller percentage (33.86\%). In $7.4 \%$ of the cases this detail was not reported. This result is well-matched with the findings of the literature in other areas (Coates, 1999, Rappaport, 2000, Jonkman and Kelman, 2005, Ashley and Ashley, 2008) and is attributed to the increased propensity for risk taking, on behalf of males. No significant changes were identified regarding the victims' gender distribution throughout the study period, with the 
exception of the first decade of the study period, which recorded 17 female fatalities, against 16 male ones. In all other decades males showed an overrepresentation amongst the decedents.

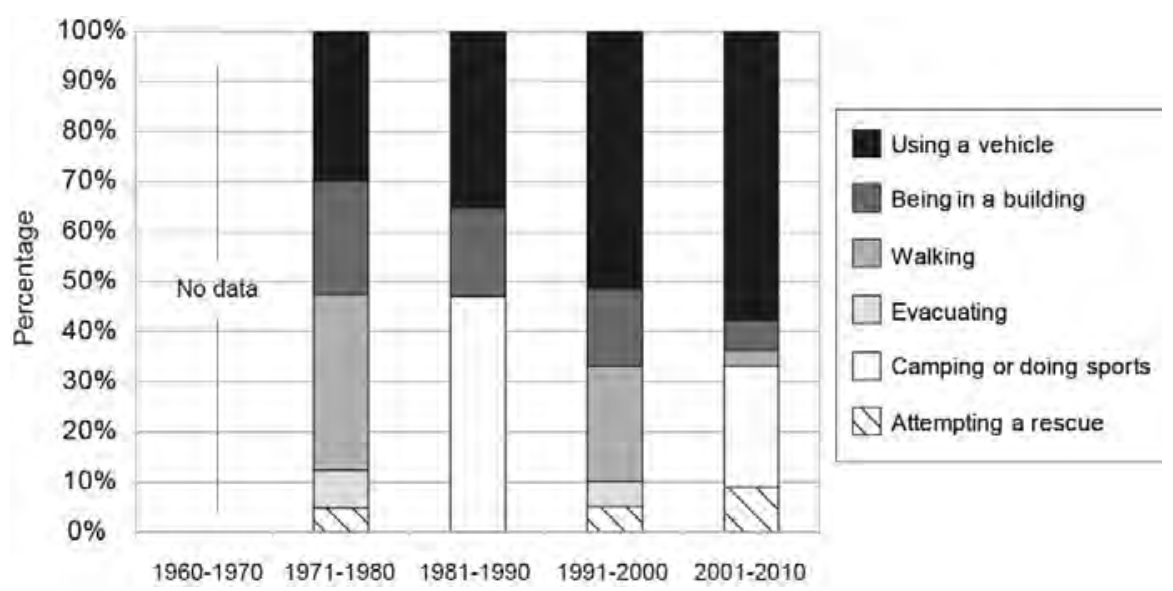

Figure 3 - Evolution of the distribution of decedents according to their activity at the time of the incident in 10-year segments.

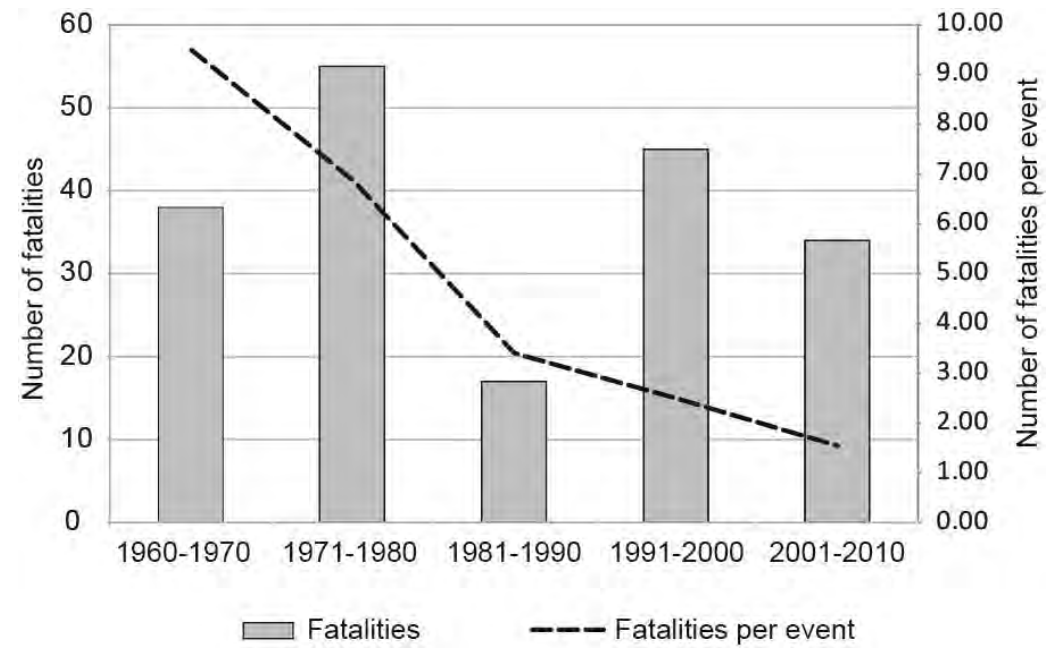

Figure 4 - Temporal evolution of flood-related deaths and deaths per flood event through the study period, in 10-year segments.

As far as the age of the victims is concerned, analysis showed an overrepresentation of youngsters ( $<15$ years old) and elderly people ( $>75$ years old) (Figure 5$)$. This distribution is well-matched with the literature findings, which ascribes it to their physical inability to flee. Victims aged between 15 and 34 showed underrepresentation attributed probably to their increased physical agility. Individuals aged between 35 and 54 years old show are slightly overrepresented. In 25 cases $(13.2 \%$ of total) the age was not reported.

Examination of the temporal evolution of the victims' age distribution showed that youngsters $(<15$ years old) and elders $(>75$ years old) presented a decline in percentage in the recent years. In fact, individuals between 20 and 64 years old showed a gradual increase among the decedents. This group recorded a $46.8 \%$ among the victims in the first ten years of the study period (19601970), a figure which increased to $82.4 \%$ in the last decade (2001-2010) (Figure 6). On the contrary, individuals younger than 20 years old presented a gradual decrease from $37.5 \%$ (in 1960 1970 ) to $5.88 \%$ (in 2001-2010). Victims over 65 years old increased until 2000, and then presented 
a negative trend. This increase of victims between 20 and 64 is probably connected with the use of vehicle-related deaths, as individuals under 18 and over 65 are not entitled to a driving license in the country. However, the cause cannot be determined with confidence with the available data.

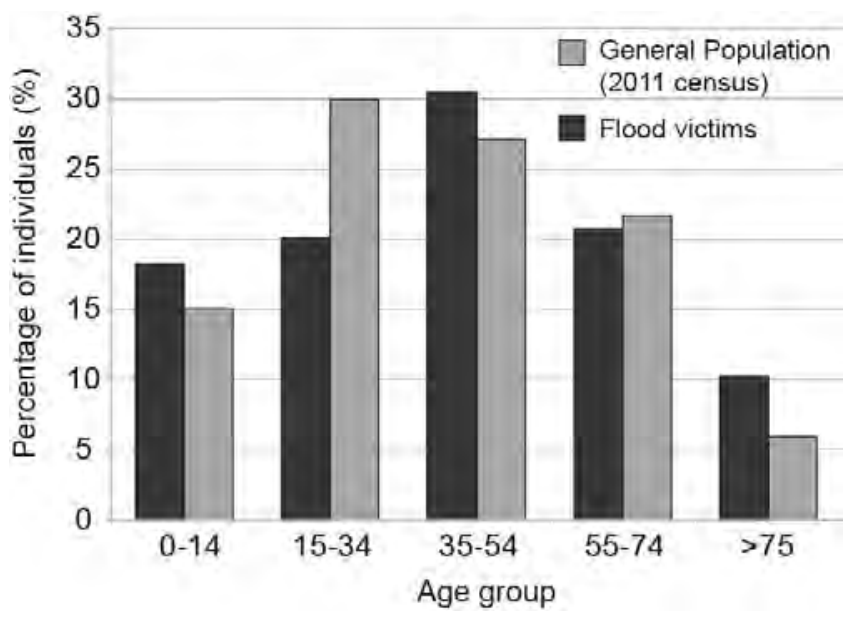

Figure 5 - Distribution of flood victims' age in comparison with the age of the general population of the country according to the 2001 census (ELSTAT 2001).

In general, this analysis shows that the development of a detailed record allows the systematic study of flood mortality and its changes and can be used as a useful tool to improve our knowledge on vulnerability of individuals to flooding. In this case, the analysis shows that the characteristics of flood mortality change in Greece, from urban high-fatality events, to low-fatality, vehiclerelated incidents in rural areas.

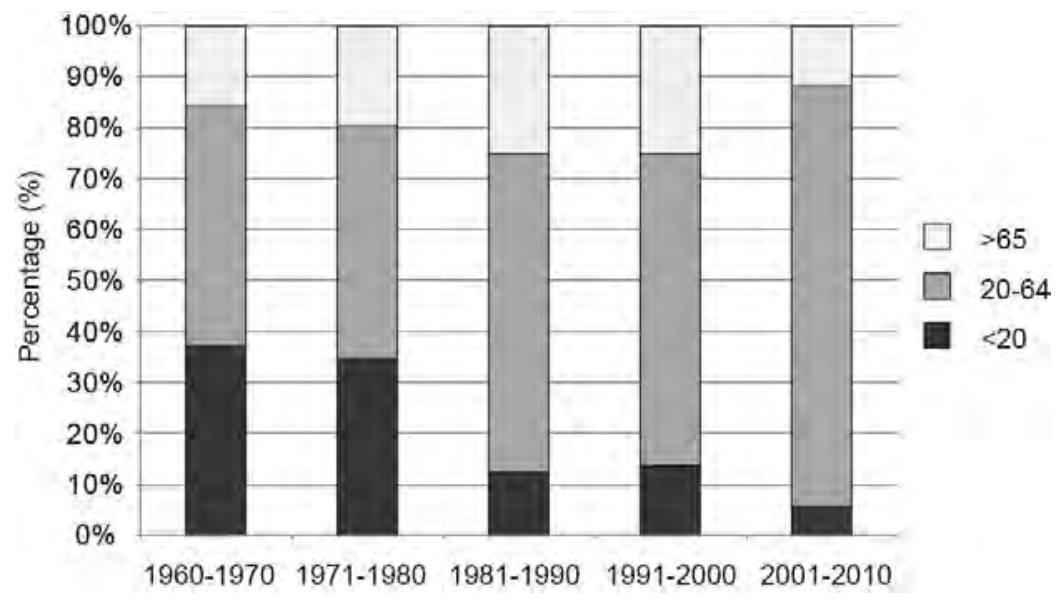

Figure 6 - Changes in distribution of flood victims' age in five segments of the time period. Individuals under 20 years old present a gradual decrease among the victims, whereas decedents between 20 and 64 years old show a continuing increase.

\section{Conclusions}

This study examines flood-related fatalities in Greece, between 1960 and 2010, and the changes that occurred in certain factors that affect flood mortality and the vulnerability of individuals to flooding. According to the findings, males, youngsters and elderly show overrepresentation among the victims, although individuals between 20 and 65 present a gradual increase during the last years of the study period. 
Fatal flood events are approximately equally divided between urban and rural settings. However, fatal incidents appear to gradually migrate from urban centers to rural environments. In addition, vehicle-related incidents present also a gradual increase, whereas pedestrian and indoor incidents are declining. High-mortality flood events are decreasing, although fatality numbers do not show a clear tendency. Drowning presents the highest percentage throughout the study period among different causes of death.

\section{References}

Alderman K., Turner L. R. and Tong S. 2012. Floods and human health: A systematic review, Environment International 47:37-47.

Ashley S.T. and Ashley W.S. 2008. Flood Fatalities in the United States, J. Appl. Meteor. Climatol., 47, 805-818.

Barrero J.I. 2009. Normalised flood losses in Europe: 1970-2006, Nat. Hazards Earth Syst. Sci. 9, 97-104.

Bern C., Sniezek J., Mathbor G.M., Siddiqi M.S., Ronsmans C., Chowdhury A.M., Choudhury A.E., Islam K., Bennish M., Noji E. and Glass R. I. 1993 Risk factors for mortality in the Bangladesh cyclone of 1991, Bull World Health Organ. 71, 1, 73-78.

Chowdhury A.R. Mushtaque A.U., Bhuyia A.Y. and Choudhury R.S. 1993. The Bangladesh Cyclone of 1991: Why So Many People Died. Disasters. 17, 4, 291-304.

Coates L. 1999. Flood fatalities in Australia, 1788-1996, Australian Geographer, 30, 3, 391-408.

Diakakis M. 2010. Flood history analysis and its contribution to flood hazard assessment. The case of Marathonas in Greece. Bulletin of the Geological Society of Greece 43(3):1323-1334.

Diakakis M., Deligianakis G. and Mavroulis S. 2011a. Flooding in Peloponnese, Greece: a contribution to flood hazard assessment, in: Lambrakis, N., Stournaras, G., Katsanou, K. (Eds) Advances in the Research of Aquatic Environment vol.1:199-206, Springer.

Diakakis M., Foumelis M., Gouliotis L. and Lekkas E. 2011b. Preliminary flood hazard and risk assessment in Western Athens metropolitan area, in: Lambrakis N, Stournaras G, Katsanou K (Eds) Advances in the Research of Aquatic Environment, vol.1:147-154, Springer.

Diakakis M., Mavroulis S. and Deligiannakis G. 2012. Floods in Greece, a statistical and spatial approach, Nat. Hazards, 62 (2), 485-500.

Digital Newspapers Collection 2010. E-efimeris: digital newspapers collection of the Greek national library. Available online at: http://www.nlg.gr/digitalnewspapers/ns/main.html.

Drobot S.D., Benight C. and Gruntfest E. C. 2007. Risk factors for driving into flooded roads, Env. Hazards, 7, 227-234.

ELSTAT 2001. De facto population by sex and age groups. Greece Total, Geographic areas (NUTS I), regions (NUTS II), departments, municipalities/communities and municipal/Communal departments. Population census 18th March 2001. Hellenic Statistical Authority ELSTAT.

French J., Ing R., Von Allmen S. and Wood R. 1983. Mortality from flash floods: a review of Nati onal Weather Service reports, 1969-81, Public Health Reports 98 (6), 584-588.

Greek National Newspapers Archive, 2010. National Newspapers Microfilm Database of the Library of the Hellenic Parliament, Hellenic Parliament, Greece.

Grothmann T. and Reusswig F. 2006. People at risk of flooding: Why some residents take precautionary action while others do not, Nat. Hazards, 38, 101-120.

Guzzetti F. and Tonelli G. 2004. Information system on hydrological and geomorphological catastrophes in Italy (SICI): a tool for managing landslide and flood hazards, Nat Hazards Earth Syst. Sci. 4, 213-232.

Jonkman S.N. 2005. Global perspectives on loss of human life caused by floods, Nat. Hazards, 34, $151-175$

Jonkman S.N. and Kelman I. 2005. An analysis of the causes and circumstances of flood disaster deaths, Disasters, 29 (1), 75-97.

$\underline{\text { XLVII, No } 3-1405}$ 
Koutroulis G., Tsanis I.K. and Daliakopoulos I.N. 2010. Seasonality of floods and their hydrometeorologic characteristics in the island of Crete. J. Hydrol. 394, 90-100.

Koutsoyiannis D. and Baloutsos G. 2000. Analysis of a long record of annual maximum rainfall in Athens, Greece, and design rainfall inferences, Nat. Hazards 29, 29-48.

Kunkel K.E., Pielke Jr.R.A. and Changnon S.A. 1999. Temporal fluctuations in weather and climate extremes that cause economic and human health impacts: a review, Bull. Amer. Meteor. Soc. 80, 1077-1098.

Lekkas E., Lozios S., Skourtsos E. and Kranis H. 1997. Floods, geodynamic environment and human intervention. The case of Corinth (Greece), Risk Analysis, Eds. C.A.Brebbia, J.L.Rubio, J.L.Uso, Wit Press, Computational Mechanics Publications, vol.2, p. 135-144.

Llasat M.C., Llasat-Botija M. and Lopez L. 2009. A press database on natural risks and its application in the study of floods in Northeastern Spain, Nat. Hazards Earth Syst. Sci. 9, 20492061.

Llasat M.C., Llasat-Botija M., Prat M.A., Porcu F., Price C., Mugnai A., Lagouvardos K., Kotroni V., Katsanos D., Michaelides S., Yair Y., Savvidou K. and Nicolaides K. 2010b. Highimpact floods and flash floods in Mediterranean countries: the FLASH preliminary database, Adv. Geosci. 23, 47-55.

Mimikou M. and Koutsoyiannis D. 1995. Extreme floods in Greece: The case of 1994. US - Italy Research Workshop on the Hydrometeorology, Impacts and Management of Extreme Floods. Perugia, Italy, 13-17 November 1995.

Mimikou M., Baltas E. and Varanou E. 2002. A study of extreme storm events in the Greater Athens area, Greece, IAHS-AISH Publication, No 271, The Extremes of the Extremes; Extraordinary Floods, 161-166.

Nikolaidou M. and Hatzichristoun E. 1995. Registering and assessment of devastating floods in Greece and Cyprus, Diploma thesis, Department of Water Resources, Hydraulic and Maritime Engineering - National Technical University of Athens, Athens.

Pradhan E.K., West K.P.Jr., Katz J., LeClerq S.C., Khatry S.K. and Shrestha S.R. 2007. Risk of flood-related mortality in Nepal, Disasters, 1, 57-70.

Rappaport E.N. 2000. Loss of life in the United States associated with recent Atlantic tropical cyclones, Bull. Amer. Meteor. Soc., 81, 2065-2073.

Ruin I., Gaillard J.C. and Lutoff C. 2007. How to get there? Assessing motorists' flash flood risk perception on daily itineraries, Environmental Hazards, 7, 235-244.

Staes C., Orengo J.C., Malilay J., Rullan J. and Noji E. 1994. Deaths Due to Flash Floods in Puerto Rico, January 1992, Implications for Prevention. International Journal of Epidemiology. 23 (5) 968-975.

Stathis D. 2004. Extreme rainfall events and flood genesis in Greece. Proceedings of the $7^{\text {th }}$ Panhellenic Geografical Conference of the Hellenic Geographical Society (7PGC/HGS), Mytilene, Greece, 1-8, 2004.

Yale J.D., Cole T.B., Garrison H.G., Runyan C.W. and RiadRuback J.K. 2003. Motor VehicleRelated Drowning Deaths Associated with Inland Flooding After Hurricane Floyd: A Field Investigation, Traffic Injury Prevention. 4 (4), 279-284.

Yeo S.W. and Blong R.J. 2010. Fiji's worst natural disaster the 1931 hurricane and flood, Disasters, 34 (3), 657-683. 